\title{
Kashırskaya AVM Projesindeki Cam Korkulukların Detaylı İncelenmesi
}

\author{
I. Ozan DEMIREL ${ }^{1}$ \\ Ahmet YAKUT ${ }^{2}$ \\ Ŭurhan AKYÜZ $Z^{3}$ \\ Hamdi YIĞIN ${ }^{4}$ \\ H. Erdinç DİKBAYIR ${ }^{5}$
}

ÖZ

Moskova Rusya'da inşa edilen Kashirskaya alışveriş merkezinde, mimari gereksinimlerle, cam korkuluklar öngörülmüştür. İmalatçı tasarımında gereken birtakım değişiklikler sonucu en çok kullanılan ve gerçek ölçülerdeki büyük panellerin yapısal güvenliğinin deneylerle doğrulanması istenmiştir. Bu amaçla cam korkulukların ve bağlantı elemanlarının 3 boyutlu sonlu elemanlar modeli oluşturularak ilgili yönetmeliklere göre taşıma gücü ve deplasman hesapları yapılıp sonuçlar ODTU Yapı Mekaniği Laboratuvarı'nda tam ölçekli cam korkuluklar üzerinde gerçekleştirilen deneylerle doğrulanmıştır.

Anahtar Kelimeler: Cam korkuluk, tam ölçekli deney, çelik profil bağlantı detayı.

\section{ABSTRACT}

\section{Detailed Investigation of Glass Balustrade in Kashırskaya Shopping Mall Project}

Glass balustrade construction, envisaged for architectural considerations, was utilised in Kashirskaya shopping center in Moscow, Russia. Modifications were required in the manufacturer's design, to be further verified by full scale tests, on the most used largest sized panels. 3-D finite element computer model of glass balustrades and connection members

\footnotetext{
Not: Bu yazı

- Yayın Kurulu'na 27 Mayıs 2019 günü ulaşmıştır. 23 Mayıs 2020 günü yayımlanmak üzere kabul edilmiştir.

- 31 Mart 2021 gününe kadar tartışmaya açıktır.

- https://doi.org/10.18400/tekderg.569821

1 Bilkent Üniversitesi, Mimarlık Bölümü, Ankara - ozan.demirel@bilkent.edu.tr https://orcid.org/0000-0002-8448-5281

2 Orta Doğu Teknik Üniversitesi, İnşaat Mühendisliği Bölümü, Ankara - ayakut@metu.edu.tr https://orcid.org/0000-0003-3664-7634

3 Orta Doğu Teknik Üniversitesi, İnşaat Mühendisliği Bölümü, Ankara - han@metu.edu.tr https://orcid.org/0000-0003-1210-8142

4 ENKA İnşaat ve Sanayi A.Ş. Tasarım Merkezi, İstanbul - hyigin@enka.com https://orcid.org/0000-0002-2319-6718

5 ENKA İnşaat ve Sanayi A.Ş. Tasarım Merkezi, İstanbul - erdinc.dikbayir@enka.com https://orcid.org/0000-0001-6063-1144
} 
were formed and ultimate capacity and service limit calculations were made according to the related regulations. Results were compared with the experiments carried out on full-scale glass balustrades tested at METU Structural Mechanics Laboratory.

Keywords: Glass balustrade, full scale experiment, steel profile connection detail.

\section{GİRIŞ}

İnşaat sektöründe korkuluk olarak uzun yıllar boyunca ahşap ve çelik malzemeler kullanılmıştır. İmalat teknolojisindeki gelişmeler ve ekonomik çözümlerin elde edilmesi sonucunda, yakın zamanda yapılan projelerde cam korkuluklar daha çok tercih edilmeye başlanmıştır. Camın, çelik ve alüminyum ile birlikte kullanılması neticesinde montaj konusunda yaşanan sorunlar da büyük ölçüde aşılmaktadır. Alışveriş merkezi (AVM), mağaza, hastane, ofis, konut balkonları ve benzeri birçok mekânda, çeşitli uygulamaları ile cam korkuluklar artık hayatımıza tamamen girmiş bulunmaktadır.

Rusya'da inşa edilen Kashirskaya Alışveriş̧ Merkezinde mimari gerekçelerle cam korkulukların kullanılması uygun görülmüştür. Söz konusu korkulukların temini için seçilen imalatçı firmanın öngördüğü tasarımda bazı sorunların ortaya çıkabileceği düşünüldüğünden tasarım kontrolü ve gerekli görülen değişikliklerin deneysel irdelenmesine ihtiyaç duyulmuştur. Bu amaçla proje kapsamında en çok kullanılan 1 tipi korkuluk için gerçek ölçülerde test modeli oluşturularak EN 1991-1.1' de [1] tanımlanan Servis Limit Durumu (SLS) ve Nihai Limit Durumu (ULS) koşulları için hesaplanan yükler, cam korkuluklara düzlem dışı yönde uygulanmıştır.

\section{CAM KORKULUKLARIN YAPISAL ÖZELLİKLERİ}

Tip 1 cam korkuluğunu oluşturan yapısal elemanlar Şekil 1'de görülmektedir. Korkuluk camı olarak temperli lamine cam (TLC) seçilmiştir. Lamine cam, iki ayrı camın, PVB isimli özel bir şeffaf plastik (Trisifol BG sınıfı) kullanılarak, ısı ve yüksek basınç altında preslenmesiyle oluşan cam çeşididir. Kırıldığı zaman, PVB ara katmanı cam parçalarının dağılmasını engeller ve bu mahallerde insan güvenliğinin sağlanması için camın büyük keskin parçalar halinde parçalanmasına izin vermez.

Ülkemizde 6331 sayılı İş Sağlığı ve Güvenliği yasası açısından cam korkulukların yatay yüklere karşı güvenilirliğinin ötesinde, camların kırılması durumunda iş güvenliğini ve kullanıcı güvenliğini sağlaması gerekmektedir. İş Sağlığı ve Güvenliği yasası kapsamına giren bütün işyerlerini kapsayan İşyeri Bina ve Eklentilerinde Alınacak Sağlık ve Güvenlik Önlemlerine İlişkin Yönetmelik’te [2] "işyerlerinde bina, avlu, geçit ve ulaşım yollarında bulunan saydam veya yarı saydam camlı bölmeler, açık bir şekilde işaretlenir, ayrıca güvenli malzemeden yapılır veya çarpma ve kırılmaya karşı korunur" denilmektedir. Çerçevesiz, kısmi çerçeve içinde veya tamamen çerçeve içinde olan koruyucu cam bariyerler TS EN 12150-1 [3]'e uygun olmalıdır. Kullanılacak koruyucu camın uygun olduğu ürün standardının, üreticisinin adı veya ticari markasının cam üzerinde açıkça ve silinmez olarak işaretlenmesi gerekmektedir [4].

Tip 1 cam korkuluğu için seçilen cam kesiti, 1,52mm kalınlığındaki PVB ara katmanı ile birleştirilen 2 adet $10 \mathrm{~mm}$ kalınlığında temperli camdan oluşmaktadır. Mesnet detayı olarak, 
korkuluğun alt kısmında yer alan ve "U" şeklinde kesite sahip bir alüminyum profil tasarlanmıştır. Bu tip cam korkulukların mesnet bağlantıları için tercih edilen en yaygın yöntem, "U" şeklindeki alüminyum profilin betonarme döşemeye dübeller yardımıyla bağlanmasıdır. Bu projeye özgü olmak üzere alüminyum profilin yerleşimi, kaplama üzerinden $100 \mathrm{~mm}$ yükseklikte bitecek şekilde tasarlanmıştır. Böylece, alüminyum profilin 100mm yüksekliğindeki kısmı aynı zamanda tekmelik olarak kullanılarak ekonomik bir çözüm elde edilmiştir. Alüminyum profil, taban levhasına kaynaklı olan 40 x 60 x 3mm boyutlarında çelik kutu profillerin üzerine oturtularak istenen yüksekliğe gelmesi sağlanmıştır. 40x60x3mm boyutlarındaki çelik kutu profil, aynı zamanda, betonarme döşeme üzerine atılan şap için kenar kalıp vazifesi görmektedir. Yapılan bu değişiklikler ile bağlantı detayı çok amaçlı olarak geliştirilmiştir.

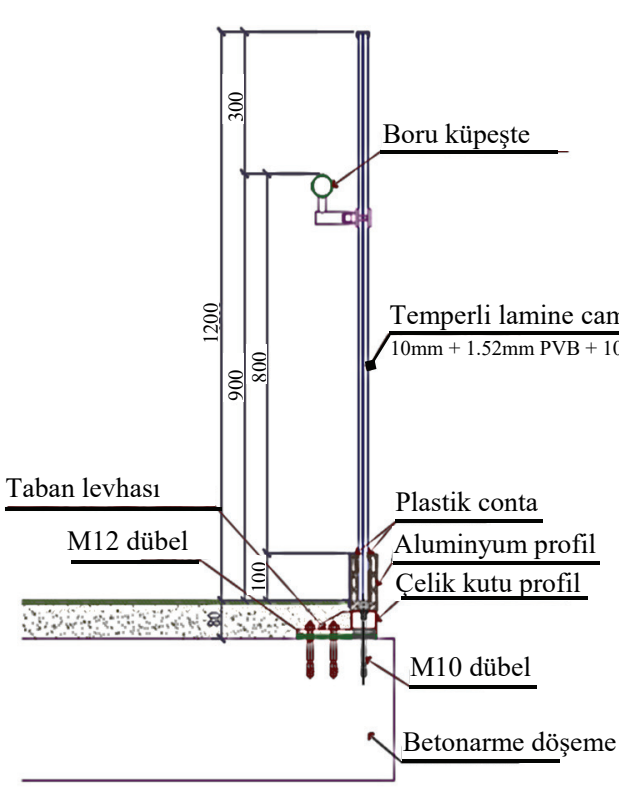

TIP-1 KORKULUK KESITI

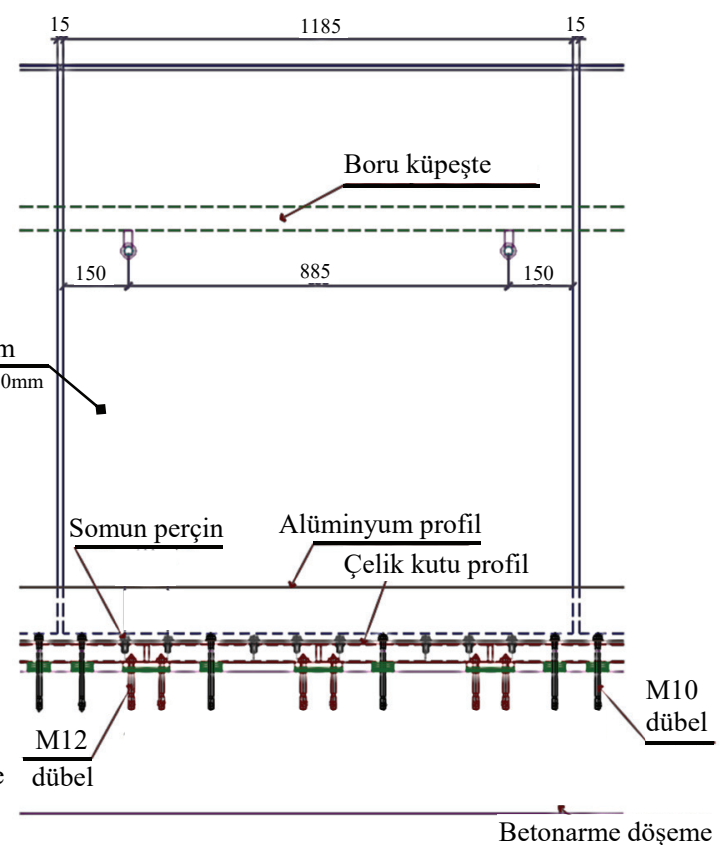

TİP-1 KORKULUK GÖRÜNÜŞÜ

Şekil 1 - Tip-1 cam korkuluğuna ait kesit ve görünüş (ölçü birimi: mm)

\section{CAM KORKULUK HESABINDA BELİRLENEN EKSİKLİKLER}

Yapısal tasarım hesaplarının incelenmesi sonucunda aşağıda belirtilen konularda daha detaylı bir araştırma yapılması gereği ortaya çıkmıştır:

- Cam korkuluğun alt kısmındaki bağlantı detayında bulunan 40x60x3mm kalınlığındaki çelik kutu profilin detaylı yapısal tahkiki yapılmalıdır.

- 40x60x3mm kalınlığındaki çelik kutu profilin, alüminyum kanal profiline bağlandığ1 noktalardaki gerilme yı̆̆glmaları kontrol edilmelidir. 
- Çelik küpeşte bağlantısı için cam üzerinde açılan deliklerin etrafında oluşan gerilme yı̆̆ılmaları kontrol edilmelidir.

\section{DENEYSEL ÇALIŞMALAR}

prEn16612 [5]' ye göre yanal yük taşıyan yapısal camlar, Servis Limit Durumu (SLS) yüklemesi altında izin verilen deplasmanlar ve Nihai Limit Durumu (ULS) yüklemesi altında maksimum gerilmeler için kontrol edilmelidir. Her iki performans durumu için kalıcı (G) ve değişken (Q) yük ile ilgili kombinasyonlar EN 1991-1.1'de şöyle tanımlanır: SLS=G+Q ve $\mathrm{ULS}=1.35 \mathrm{G}+1.5 \mathrm{Q}$. Kalıcı yük $(\mathrm{G})$, camın boyutlarından ve birim ağırlığından $(\rho=$ $2500 \mathrm{~kg} / \mathrm{m}^{3}$ ) hesaplanırken, alışveriş alanları için parapetlere etki eden yatay uygulanan yüklerin (Q) Tablo 6.12 'de $0.8 \mathrm{kN} / \mathrm{m}$ ila $1.0 \mathrm{kN} / \mathrm{m}$ aralığında olması gerektiği belirtilmiştir.

Bu projede kullanılacak olan Tip-1 korkuluk sisteminin yanal yük deplasman ilişkisi ODTÜ Yapı Mühendisliği Laboratuvarı'nda gerçekleştirilen tam ölçekli düzlem dışı testle belirlenmiştir. Temperli camların yük altında deplasmanı ortam sıcaklığı ve yükün uygulanma suresine bağlı olarak değişmektedir. Deney sırasında yatay yükler prEN 16613 [6]' e göre kalabalık merkezler için insan yükünü temsil edecek şekilde oda sıcaklığında ve 5 dakika süreyle uygulanmıştır. Camın farklı kotlarındaki düzlem dışı yer değiştirmelerine karşı yanal yük izlenmiştir.

\subsection{Deney Numunesi ve Kurulumu}

$1200 \mathrm{~mm}$ yüksekliğinde, $1185 \mathrm{~mm}$ genişliğinde ve $21.52 \mathrm{~mm}$ kalınlığında (10 mm cam + $1.52 \mathrm{~mm}$ PVB + $10 \mathrm{~mm}$ cam) tam ölçekli temperli lamine cam, ABS kamalar ile alüminyum U kanallı cam destek profiline takılmıştır. Alüminyum profil, her 100/200 mm'de bir kör perçin somunları ile $40 \times 60 \times 3 \mathrm{~mm}$ çelik dikdörtgen profile bağlanmıştır. Dikdörtgen profilin beton kaide bağlantısı her 400 mm'de bir yerleştirilen $10 \mathrm{~mm}$ kalınlığında çelik çapa plakaları ile sağlanır. Bu plakalar dikdörtgen profile kaynaklanmış ve iki adet $12 \mathrm{~mm}$ çelik dübel ile beton tabana tutturulmuştur. Ek olarak, taban pabucu, her 300/400 mm'de bulunan $10 \mathrm{~mm}$ çelik dübel ile doğrudan beton tabana bağlanmıştır (Şekil 2).

Manuel olarak kontrol edilen bir hidrolik kriko, bir adet 2 ton kapasiteli S tipi yük hücresi ve dokuz farklı boyutta doğrusal değişken yer değiştirme transdüseri (LVDT) içeren bir test düzeneği, lamine cam korkuluğun düzlem dışı testi için kullanılmıştır. Yer değiştirme okumaları tepede, küpeşte seviyesinde ve camın altında alınmıştır (Şekil 3). Taban plakasındaki olası dönmelerin hesabı için ilave yer değiştirme transdüserleri kullanılmıştır.

\subsection{Yükleme}

Alışveriş merkezlerinde yapısal cam elemanlar için hareketli tasarım yükü EN1991'de 0.8 ila $1.0 \mathrm{kN} / \mathrm{m}$ arasında olacak şekilde tanımlanmıştır. Bu çalışmada servis limit durumu ve nihai limit durumu yük kombinasyonları göz önüne alınarak $0.8,1.0,1.5$ ve $2.0 \mathrm{kN} / \mathrm{m}$ yatay yük seviyeleri seçilmiştir. Her hedef yük yaklaşık 60 saniye içerisinde uygulanmıştır. 


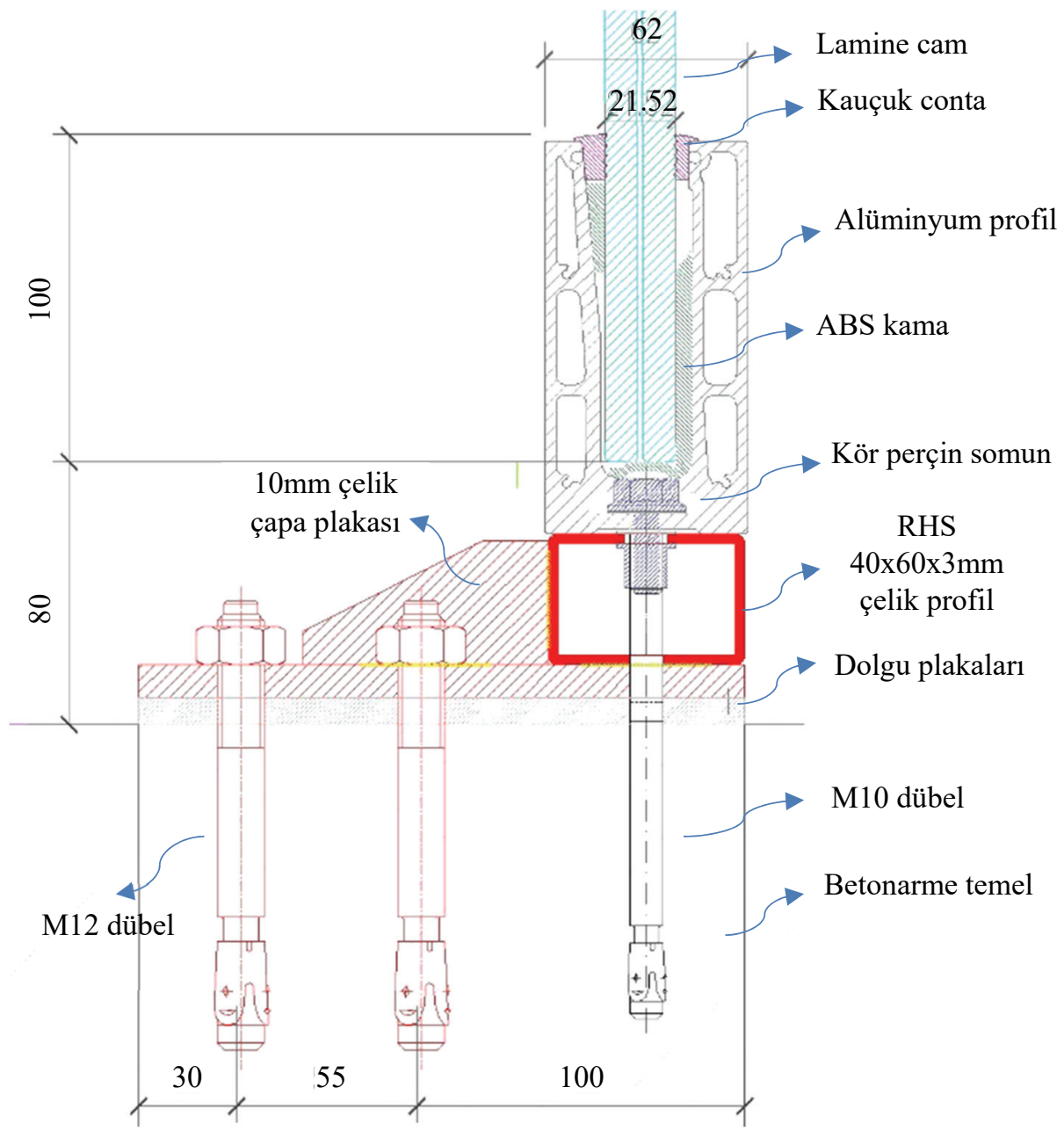

Şekil 2 - Temel bağlantı detayı

\subsection{Deney Sonuçları}

TLC korkuluktaki yer değiştirmeler, iki uçta aynı yükseklikte bulunan LVDT'lerin ortalaması alınarak hesaplanmıştır. Şekil 4'den görüleceği gibi TLC korkuluk yanal doğrultuda doğrusal elastik bir davranış göstermiştir. Her yükleme boşaltıldığında, TLC korkuluk plastik deformasyon olmadan orijinal konumuna geri dönmüştür (Şekil 5). Deneyde ölçülen azami deplasmanlar Tablo l'deki servis limitiyle birlikte gösterilmektedir. $\delta_{\text {balustrade }}$ küpeşte seviyesindeki, $\delta_{\text {tip }}$ tepe noktadaki yer değiştirmeye karşıllk gelir. prEN16612'de servis yükleri altında 5 dakika sonunda müsaade edilen en yüksek tepe nokta yer değiştirmesi L/65 veya $50 \mathrm{~mm}$ 'den küçük olanıdır. (SLS kombinasyonunda servis kolaylığı sınırı $\geq \mathrm{L} / 65=1280 / 65=19.7 \mathrm{~mm}$ ). 


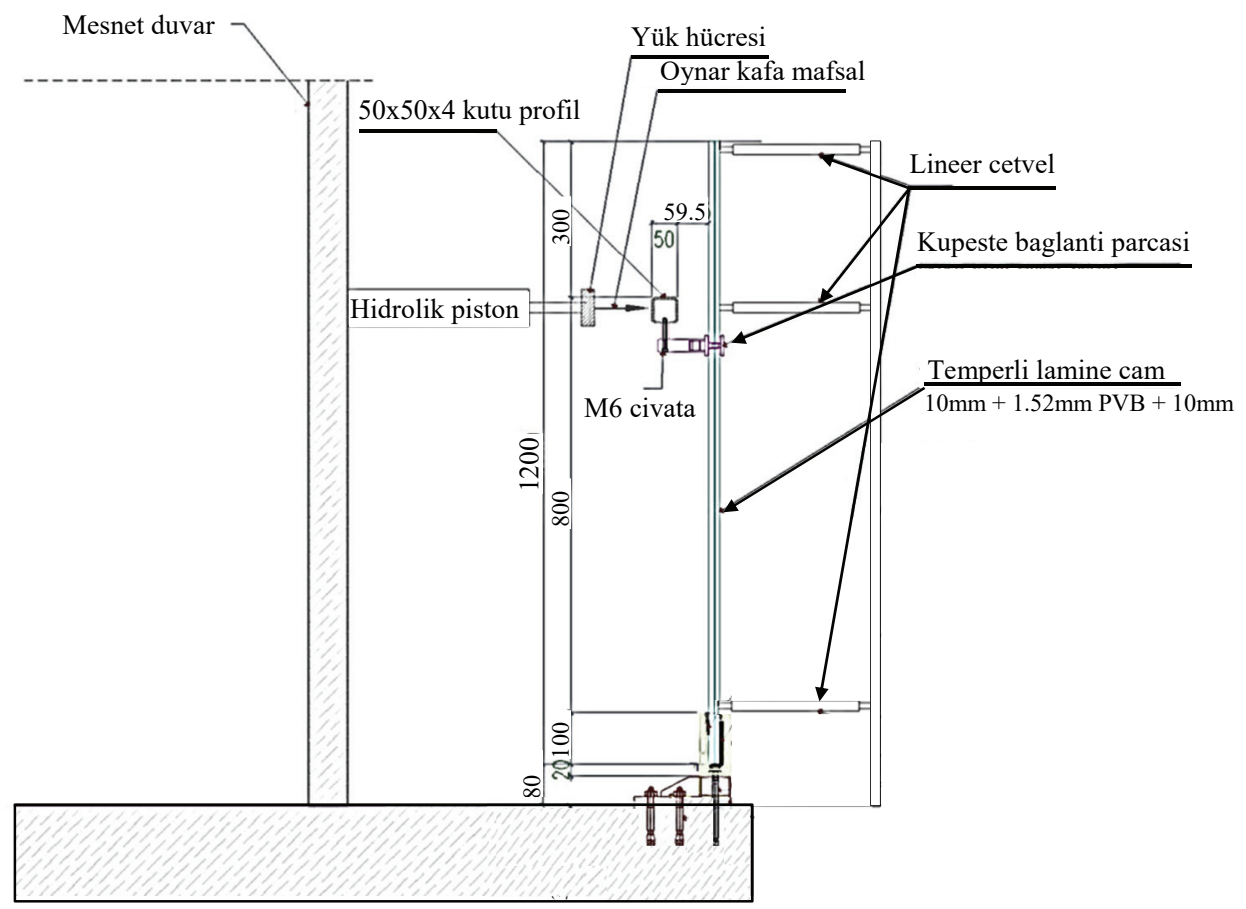

Şekil 3 - Deney kurulumu - yan görünüm

Doğrusal enterpolasyon kullanılarak, izin verilen deplasman sınırına denk gelen hareketli yük $\mathrm{q}_{\mathrm{k}}=0.97 \mathrm{kN} / \mathrm{m}$ olarak hesaplanmıştır. Bu yük EN 1991-1-1'de hareketli yükler için tanımlanan sinırlar (örn. $0.8 \mathrm{kN} / \mathrm{m}-1.0 \mathrm{kN} / \mathrm{m}$ arası) içindedir.

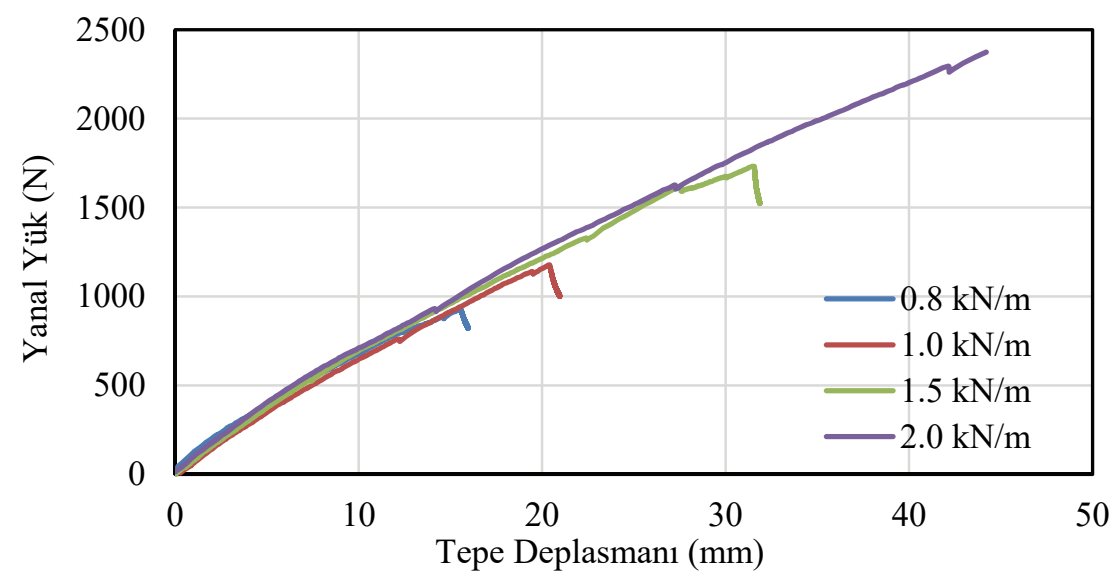

Şekil 4 - Farkl yük hedefleri için yük deplasman ĕgrileri 

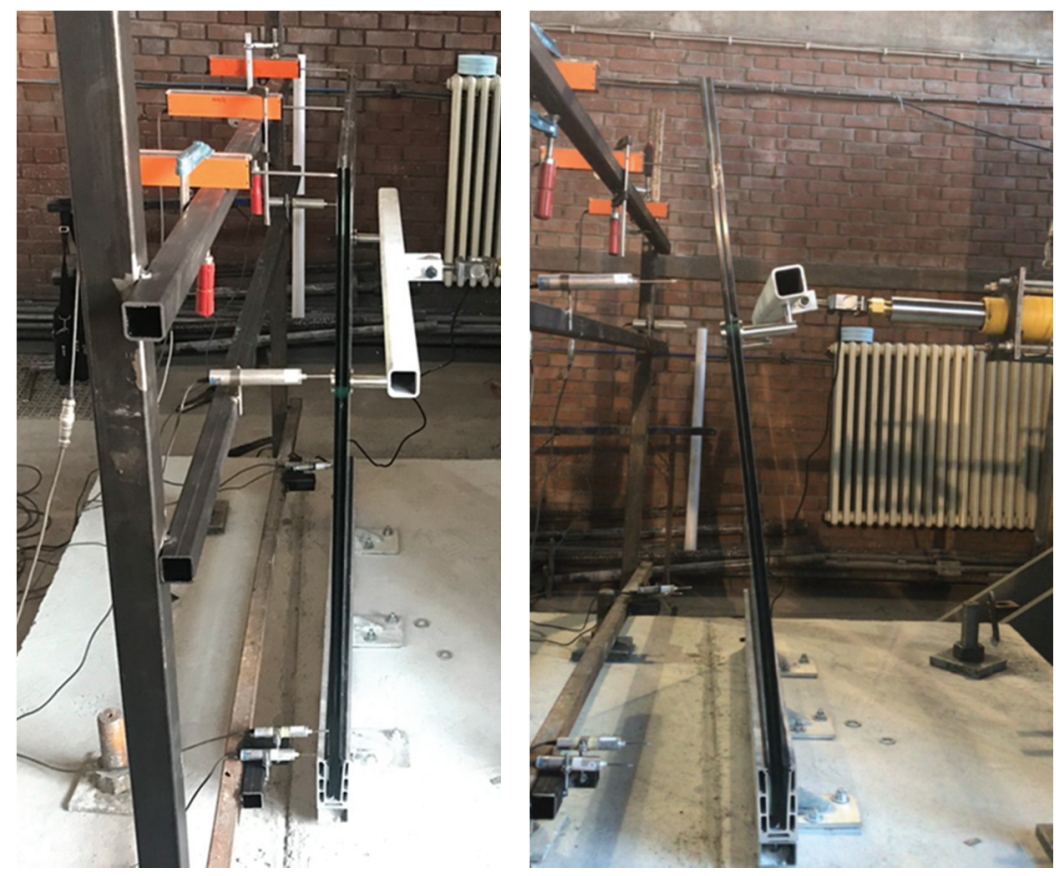

Şekil 5 - Yük altında elastik korkuluk deformasyonu

Tablo 1 - 5 dakikalı yükleme sonrası test sonuçları

\begin{tabular}{|c|c|c|c|}
\hline Yük sinıf & $\begin{array}{c}\text { Kuvvet } \\
(\mathrm{N})\end{array}$ & $\begin{array}{c}\boldsymbol{\delta}_{\text {balustrade,5dak }} \\
(\mathrm{mm})\end{array}$ & $\begin{array}{c}\boldsymbol{\delta}_{\text {tip,5dak }} \\
(\mathrm{mm})\end{array}$ \\
\hline $\begin{array}{c}\mathrm{SLS} \\
(\mathrm{qk}=0.8 \mathrm{kN} / \mathrm{m})\end{array}$ & 927 & 11,0 & 15,6 \\
\hline $\begin{array}{c}\mathrm{SLS} \\
(\mathrm{qk}=1,0 \mathrm{kN} / \mathrm{m})\end{array}$ & 1175 & 14,5 & 20,4 \\
\hline $\begin{array}{c}\mathrm{ULS} \\
(\mathrm{qk}=1,5 \mathrm{kN} / \mathrm{m})\end{array}$ & 1719 & 22,1 & 31,2 \\
\hline $\begin{array}{c}2.5 \mathrm{ULS} \\
(\mathrm{qk}=2,0 \mathrm{kN} / \mathrm{m})\end{array}$ & 2350 & - & - \\
\hline
\end{tabular}

\section{ANALITIIK ÇALIŞMALAR}

\subsection{Yapısal Model (SAP2000)}

TLC korkulukların deplasman ve gerilme hesapları etkili kalınlık yöntemine göre yapılmıştır [5]. Bu amaçla Şekil 6'da verilen 3 boyutlu yapisal sonlu elemanlar modeli SAP2000 v19.2.1 yazılımı [7] kullanılarak oluşturulmuştur. Malzeme özellikleri Tablo 2'ye göre tanımlanmıştır. Kontak yüzeyleri sadece basınç yaylarıyla, dübeller sadece çekme yaylarıyla modellenmiştir. 


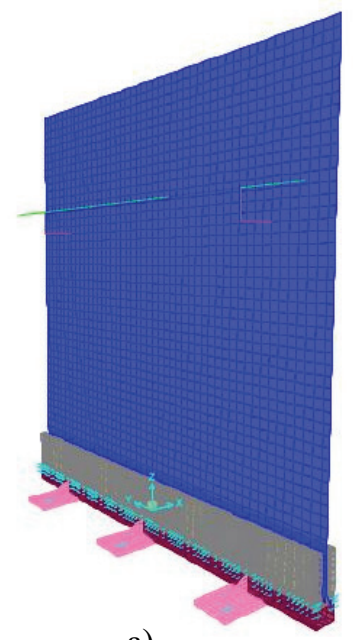

a)

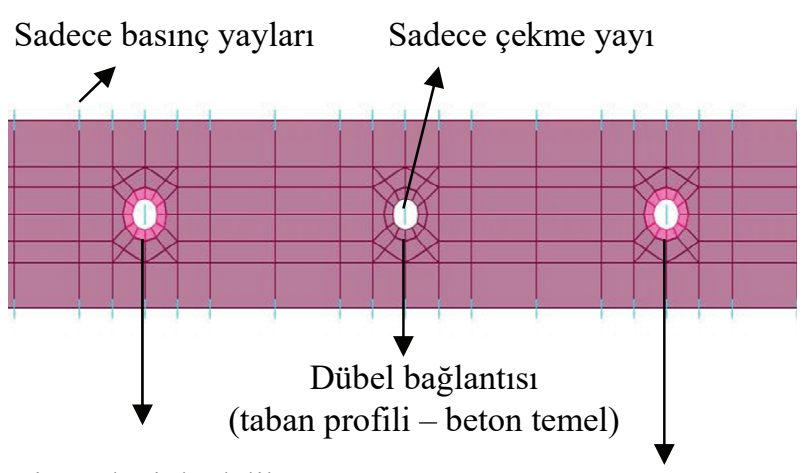

Perçin nedeniyle delik etrafının artan kalınlığı
Perçin bağlantı (taban profili - RHS)

b)

Tablo 2 - Malzeme Özellikleri

\begin{tabular}{|c|c|c|c|c|c|c|c|}
\hline Malzeme & Sinıfi & $\begin{array}{c}\mathrm{E} \\
(\mathrm{MPa})\end{array}$ & $v$ & $\begin{array}{c}\rho \\
\left(\mathrm{kg} / \mathrm{m}^{3}\right)\end{array}$ & $\begin{array}{c}\mathrm{f}_{\mathrm{ck}} \\
(\mathrm{MPa})\end{array}$ & $\begin{array}{c}\mathrm{f}_{\mathrm{yk}} \\
(\mathrm{MPa})\end{array}$ & $\begin{array}{c}\mathrm{f}_{\mathrm{uk}} \\
(\mathrm{MPa})\end{array}$ \\
\hline Çelik Profil & S235 & 200,000 & 0,30 & 7850 & - & 235 & 360 \\
\hline Dübel & Sormat S-KA & 200,000 & - & - & - & 560 & 660 \\
\hline Cam & - & 70,000 & 0,22 & 2500 & - & - & - \\
\hline Interlayer (PVB) & Trisifol Bg & - & - & - & - & - & - \\
\hline Alüminyum & - & 70,000 & 0,30 & 2715 & - & 205 & 245 \\
\hline ABS plastik & - & 2500 & 0,35 & 1050 & - & - & - \\
\hline Beton & $\mathrm{C} 30 / 37$ & 32,000 & - & - & 30 & - & 0 \\
\hline Kaynak & - & - & - & - & - & - & 360 \\
\hline
\end{tabular}

\subsection{TLC Tasarımının Dayanımı}

Ön germeli cam için eğilme dayanımı tasarım değeri aşağıdaki formülden hesaplanır [5]:

$$
f_{g, d}=\frac{k_{m o d} \times k_{s p} \times f_{g, k}}{\gamma_{M, A}}+\frac{k_{v}\left(f_{b, k}-f_{g, k}\right)}{\gamma_{M, v}}
$$

$\mathrm{Bu}$ formüle göre gerilme kontrolünde kullanılacak ULS'deki TLC'nin tasarım eğilme dayanımı $81.75 \mathrm{MPa}$ olarak hesaplanmıştır. Şekil 7'de verilen ULS yüklemesi altındaki TLC'nin gerilme dağılımında görüleceği gibi maksimum gerilme kuvveti $\sim 38 \mathrm{MPa}(<81.75$ $\mathrm{MPa}$ ) civarındadır. 

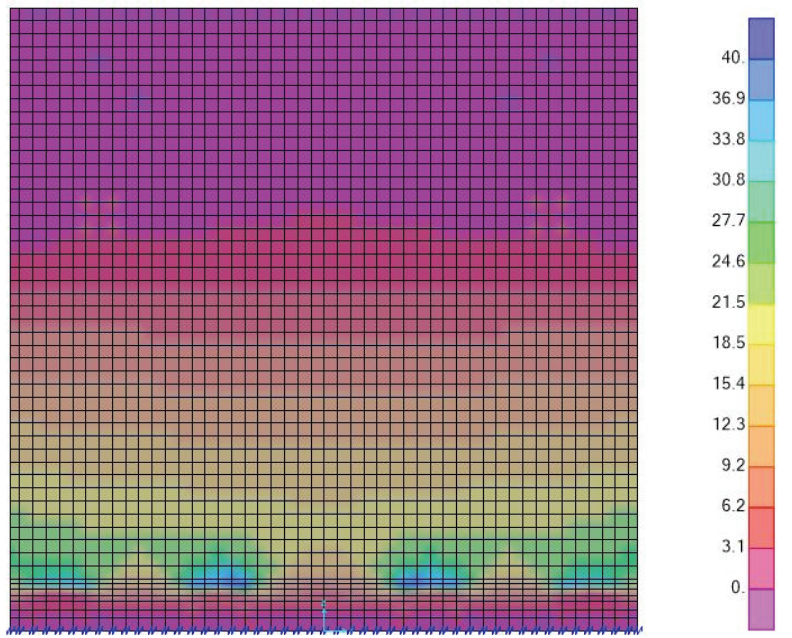

Şekil 7 - ULS yüklemesi gerilme dăğlımı, MPa (Sap2000)

\subsection{Küpeşte için Açılan Delik Kontrolü}

Analitik çalışmada TLC'de küpeşte için açılan deliğin etrafindaki gerilme konsantrasyonunu kontrol etmek için lamine camın 3B FEM modeli $(10 \mathrm{~mm}$ cam $+1,52 \mathrm{~mm}$ PVB $+10 \mathrm{~mm}$ cam) ANSYS yazılımı [8] kullanılarak üretilmiştir (Şekil 8). Pilkey [9] tarafından önerilen basitleștirilmiş yaklaşımda gerilme konsantrasyonu için K faktörü kullanılması önerilmiştir. $\mathrm{Bu}$ yaklaşıma göre delik ihmal edilerek bulunan gerilmeler $\mathrm{K}$ faktörü ile çarpılarak delikli durum için oluşacak maksimum gerilmeler tahmin edilmektedir. Bu projede kullanılan delik için Pilkey'nin önerdiği yaklaşımdan K faktörü 2.27 olarak hesaplanmıştır. Şekil 8’de delik etrafinda okunan maksimum gerilme $18.37 \mathrm{MPa}$ 'dır. Bu durumda delikteki maksimim gerilme yığılması 18.37 x2.27=41.8 MPa $(<81.75 \mathrm{MPa})$ olmaktadır.

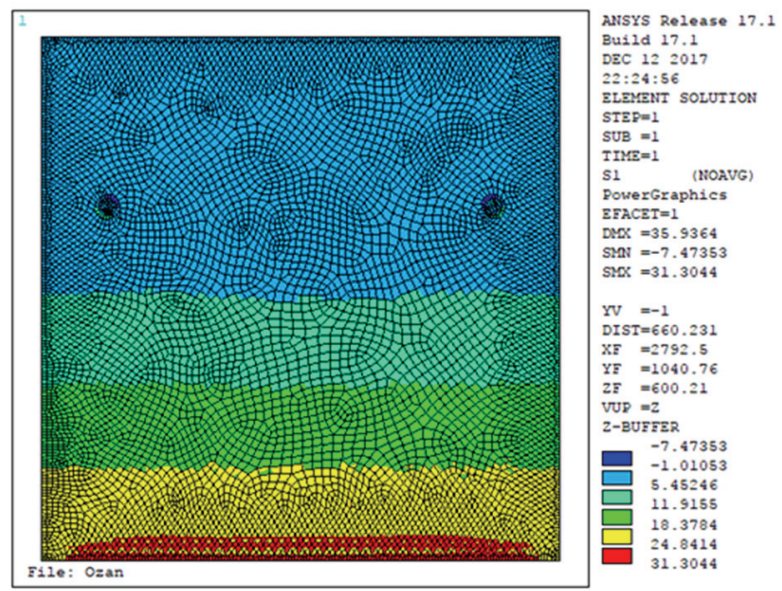

Şekil 8 - Küpeşte deliği ANSYS modeli 


\subsection{Taban Plakaları Gerilme Kontrolü}

Bu bölümde taban levhası ve çelik kutu profil üzerindeki gerilme değerleri hesaplanmış ve çeliğin akma dayanımıyla karşılaştırılmıştır (Şekil 9). Taban levhasında meydana gelen gerilmelerin müsaade edilen gerilme değerini aşmadığ 1 görülmüştür. $40 \times 60 \times 3 \mathrm{~mm}$ çelik kutu profilin, alüminyum profile bağlandığı noktalarda, delik kenarından $3,5 \mathrm{~mm}$ mesafe içerisinde kalan kısıtlı bir bölgede gerilme yığılmaları nedeniyle müsaade edilen gerilmenin aşıldığı görülmüştür. Delik kenarı gerilmeler Şekil 9'da görülmektedir. SAP 2000 modelinden alınan mesnet reaksiyonları kullanılarak, ETAG 001'e [10] göre yapılan hesaplar sonucunda dübellerin yeterli kapasitede olduğu tespit edilmiştir.
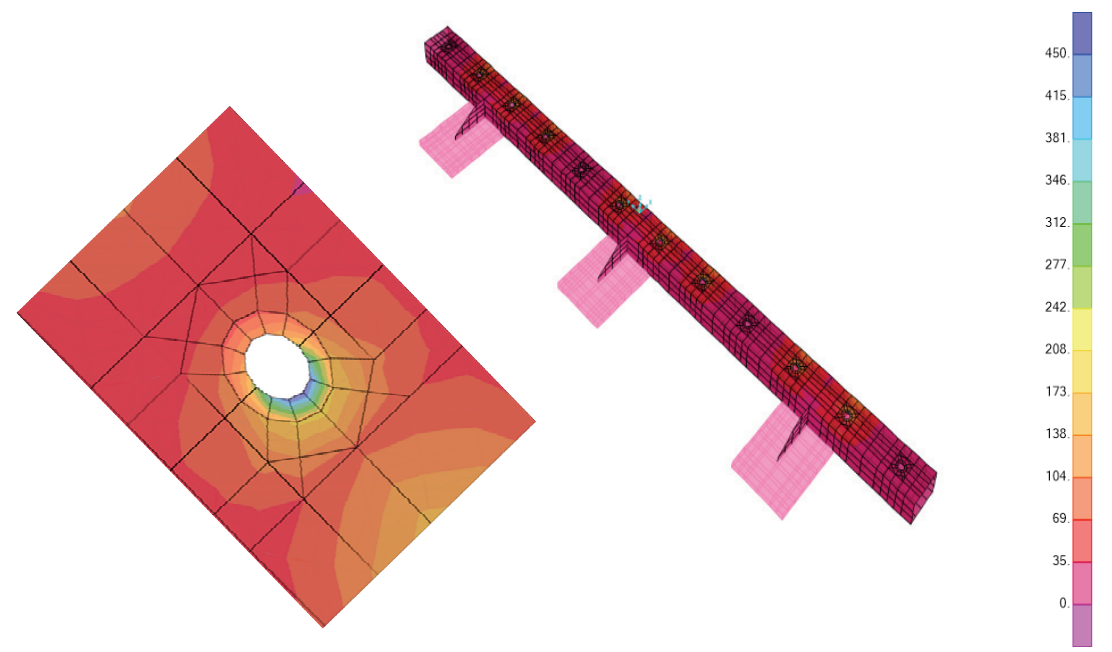

Şekil 9 - Taban plakaları Von Misses gerilmeleri, MPa

\section{SONUÇ}

Kashirkaya Alışveriş Merkezi için ENKA Tasarım Merkezi İnşaat Grubu tarafından tasarımı gerçekleştirilen temperli lamine cam (TLC) korkuluk ODTÜ İnşaat Mühendisliği Bölümü Yapı Mühendisliği Laboratuvarı'nda bire bir ölçekli deneysel çalışmaya tabi tutulmuş ve analitik olarak incelenmiştir. Çalışma sonucunda aşağıdaki sonuçlara varılmıştır:

- Cam korkuluk tasarım yükleri altında yeterli dayanım göstermiştir, deney sırasında ölçülen deplasmanlar ilgili şartname sınırları içerisinde kalmıştır.

- Cam üzerinde açılan deliklerin kenarlarındaki gerilme yığılmalarının sınır gerilme değerinin altında kaldığı görülmüştür.

- Yapılan analizler neticesinde, mesnet bölgelerinde yer alan çelik dübellerin, taban levhalarının, taban levhası üzerindeki kaynakların ve çelik kutu profilin yeterli yük taşıma kapasitesine sahip olduğu görülmüştür.

- $40 \times 60 \times 3 \mathrm{~mm}$ ebatlarındaki çelik kutu profil ile alüminyum profilin bağlantı noktalarında, çelik profil üzerinde açılan deliklerin kenarlarında oluşan gerilme yığılmaları incelenmiştir. Gerilme yı̆̆ılmalarının, müsaade edilen gerilme değerini ancak çok küçük bölgelerde aştığ 1 ve bu hususun, profilin taşıma gücüne olumsuz bir etkisinin olmayacağı tespit edilmiştir. 


\section{Semboller}

$\mathrm{f}_{\mathrm{g}, \mathrm{d}} \quad$ : eğilme dayanımının tasarım değeri,

$\mathrm{f}_{\mathrm{g}, \mathrm{k}} \quad$ : cam bükülme dayanımının karakteristik değeri $\left(\mathrm{f}_{\mathrm{g}, \mathrm{k}}=45 \mathrm{MPa}\right.$, Ek C [3]),

$f_{b, k} \quad$ : öngerilmeli camın bükülme mukavemetinin karakteristik değeri $\left(f_{b, k}=\right.$ termal olarak sertleştirilmiş şamandıra emniyet camı için $120 \mathrm{MPa}$, Tablo 7 [3]),

$\gamma_{\mathrm{m}, \mathrm{a}}$ : tavlanmış cam için malzeme faktörü $\left(\gamma_{\mathrm{m}, \mathrm{a}}=1.8\right.$, Tablo $\left.2[3]\right)$,

$\gamma_{\mathrm{m}, \mathrm{v}}$ : yüzey ön gerilimi için malzeme faktörü $\left(\gamma_{\mathrm{m}, \mathrm{v}}=1.2\right.$, Tablo $\left.2[3]\right)$,

$\mathrm{k}_{\mathrm{v}}$ : önceden gerilmiş camın güçlendirme faktörü (yatay sertleştirme için $\mathrm{k}_{\mathrm{v}}=1$, Tablo 8 [3]),

$\mathrm{k}_{\mathrm{sp}} \quad$ : cam yüzey profili için faktör (yüzer cam için $\mathrm{k}_{\mathrm{sp}}=1$, Tablo 5 [3])

$\mathrm{k}_{\bmod }$ : yük süresinin faktörüdür $\left(\mathrm{k}_{\bmod }=0.77\right.$, insan yük kalabalıkları için, Tablo 6 [3]).

\section{Kaynaklar}

[1] EN 1991-1-1 (2002) Eurocode 1: Actions on structures Part 1: General actions Densities, self-weight, imposed loads for buildings.

[2] İşyeri Bina ve Eklentilerinde Alınacak Sağlık ve Güvenlik Önlemlerine İlişkin Yönetmelik (2013), Çalışma ve Sosyal Güvenlik Bakanlığı, Ankara.

[3] TS EN 12150-1:2015+A1: Cam - Yapılarda kullanılan - Isıl olarak temperlenmiş soda kireç emniyet camları - Bölüm 1: Tanımlar ve açıklamalar, Türk Standartları Enstitüsü, Ankara.

[4] TS 13433 (2010) Cam - Yapılarda kullanılan - İnsan çarpmasıyla ilgili güvenlik için uygulama kuralları, Türk Standartları Enstitüsü, Ankara.

[5] prEN 16612 (2017-05) Glass in building - Determination of the lateral load resistance of glass panes by calculation.

[6] prEN 16613 (2017-05) Glass in building - Laminated glass and laminated safety glass - Determination of interlayer mechanical properties.

[7] SAP2000 v19.2 Integrated Finite Element Analysis and Design of Structures. CSI, Berkeley, USA.

[8] ANSYS, ANSYS Inc., Southpointe 2600 ANSYS Drive Canonsburg, PA 15317, USA.

[9] Pilkey, W. D. \& Pilkey, D. F. (1997). Peterson's stress concentration factors. John Wiley and Sons, Inc., ISBN 0-471-53849-3, New York.

[10] ETAG 001-1 (2013): Guideline for European technical approval of metal anchors for use in concrete - Part one: Anchors in general. 
